\title{
Teaching and Assessment through Online Platforms during the COVID-19 Pandemic: Benefits and Challenges
}

\author{
Adebunmi Yetunde Aina ${ }^{1 \ltimes}$ \\ Ayodele Abosede Ogegbo ${ }^{2}$
}

'Department of Educational Management and Policy Studies, University of Pretoria South Africa.

'Email:ay.aina@up.ac.za Tel +27747120082

${ }^{2}$ Department of Science and Technology Education, University of Johannesburg South Africa.

¿Email:ayo3108@yahoo.com Tel: +27743296486

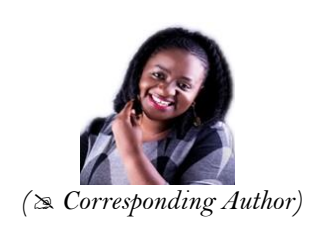

\begin{abstract}
The outbreak of the COVID-19 pandemic has compelled education systems across the globe to fully embrace online learning as an alternative to face-to-face classes. This has resulted in a paradigm shift, in which online teaching and assessment practices continue to gain prominence at the tertiary level. Hence, this study explores lecturers' teaching and assessment strategies for teaching university students through online platforms during the COVID-19 pandemic. This study has used a framework of SWOT (strength, weakness, opportunities, and threats) analysis as its theoretical base. Data was collected through semi-structured interviews with five lecturers from three universities in Gauteng Province, South Africa. The collected data was analysed using content analysis. This study found that lecturers were able to manage the teaching and assessment processes during the COVID-19 school restrictions, using a combination of platforms such as Blackboard-collaborate, WhatsApp, Kahoot, and Google Classroom. The findings also revealed that a wide variety of teaching and assessment methodologies, including small group work, collaborative learning, case methods, discussion posts, multiple choice quizzes, chats, game activities, open-ended questions, and essays were utilized on these platforms. Although the methodologies used for teaching and assessing on these platforms require additional preparation time, they also help increase interaction between students and enable immediate grading of scripts and student feedback. Further findings revealed that online assessment is highly susceptible to test/examination malpractices. This study provided recommendations helpful to policymakers, lecturers, and students regarding online teaching and assessment strategies.
\end{abstract}

Keywords: Assessment strategies, COVID-19, Higher Institution, Lecturer, Online platforms, Teaching strategies.

Citation | Adebunmi Yetunde Aina; Ayodele Abosede Ogegbo (2021). Teaching and Assessment through Online Platforms during the COVID-19 Pandemic: Benefits and Challenges. Journal of Education and e-Learning Research, 8(4): 408-415. History:

Received: 22 September 2021

Revised: 26 October 2021

Accepted: 29 November 2021

Published: 20 December 202

Licensed: This work is licensed under a Creative Commons Attribution 3.0 License (cc) EY

Publisher: Asian Online Journal Publishing Group
Acknowledgement: Both authors contributed to the conception and design of the study.

Funding: This study received no specific financial support.

Competing Interests: The authors declare that they have no conflict of interests.

Transparency: The authors confirm that the manuscript is an honest, accurate, and transparent account of the study was reported; that no vital features of the study have been omitted; and that any discrepancies from the study as planned have been explained.

Ethical: This study follows all ethical practices during writing.

\section{Contents}

1. Introduction

2. A Review of Related Literature

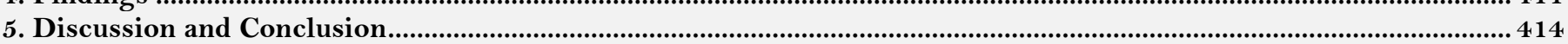

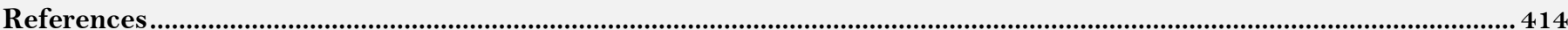




\section{Contribution of this paper to the literature}

This study contributes to existing literature by exploring lecturers' teaching and assessment strategies for teaching university students through online platforms during the COVID-19 pandemic.

\section{Introduction}

The COVID-19 pandemic has helped accelerate the incorporation of online teaching and learning in higher education institutions to prevent the spread of the virus by reducing human contact. Recent research indicates that universities across the globe now exclusively conduct teaching and assessment via online platforms to limit the spread of the virus and ensure continuity of teaching and learning (Coman, Țîru, Meseşan-Schmitz, Stanciu, \& Bularca, 2020). Among the many benefits of online learning is the possibility of teaching and learning at any time and anywhere (remotely), engaging the diverse audience, cost-effectiveness, increased access to online information, the use of tools to measure learning outcomes, and facilitated collaboration between students and educators (Mwapwele, Marais, Dlamini, \& Van Biljon, 2019; Parlakkiliç, 2017; Ramorola, 2013; Torres \& Giddie, 2020). However, there seem to be gaps in the research on the strategies and methodologies used by lecturers to facilitate effective teaching and authentic assessment via online learning platforms, and especially the benefits and challenges of the various methods employed by lecturers to facilitate teaching and assessment via online learning platforms.

The facilitation of teaching and assessment via online learning platforms demands different strategies than traditional face-to-face learning. According to Hew and Cheung (2014), learning via an online learning platform involves a greater workload than learning in a traditional classroom. Barrett (2010) echoes that online lecturers must have different types of skillsets to compete in today's online learning environment. For these reasons, lecturers must develop and improve their online teaching strategies and methodologies to offer the effective teaching and learning that the present situation requires. The main question that needs to be answered is what the benefits and challenges are of the strategies employed by university lecturers to facilitate effective teaching and assessment during COVID-19 school closures. Knowledge of the benefits and challenges of the teaching and assessment strategies used in online learning will provide clarity regarding the most effective teaching strategies for online learning, the relevant issues related to online teaching and assessment, as well as what to do to counter the challenges encountered during online teaching and assessment in higher education.

Hence, this study explores lecturers' teaching and assessment strategies on online platforms when teaching university students during and after the COVID-19 restrictions. The aim of exploring the teaching and assessment strategies is to identify the benefits and challenges associated with the teaching and assessment strategies used by the lecturers. Thus, the research questions to address the aim of this study are:

- What teaching methodologies are used by lecturers to facilitate online learning during COVID-19 school restrictions?

- What methods of assessment are used by lecturers on online platforms during COVID-19 school restrictions?

- How does the online environment facilitate or constrain effective teaching and assessment during the COVID-19 school restrictions?

The next section will present an overview of the related literature, followed by a description of the SWOT (strength, weakness, opportunities, and threats) framework. This framework is used as the conceptual basis for the exploration and discussion of the benefits and challenges of the teaching and assessment strategies used by the selected university lecturers via online platforms.

\section{A Review of Related Literature}

\subsection{Teaching and Learning through Online Learning Platforms}

Online learning platforms have helped to ensure continuity of teaching and learning during the COVID-19 pandemic-associated school lockdown. An online learning platform is a desegregated set of interactive online facilities that provide teachers, learners, and others with information, tools, and resources to support and enhance educational delivery and management (SAP Litmos, 2021). Different higher education institutions have adopted various online learning platforms; the learning platform adopted determines the possible teaching activities and the level of interaction and engagement between the lecturer and students. Before COVID-19, the use of online platforms was supplementary to traditional face-to-face learning. Recently, however, learning in higher education institutions has been predominantly conducted via online platforms. It is essential to know whether the actual purpose of teaching and learning is being achieved via online teaching. Studies have shown various benefits of teaching via online platforms, such as its potential to provide synchronous and asynchronous learning through emails, discussion forums, videos, and live sessions (Anwar \& Adnan, 2020; Marinoni, Van't Land, \& Jensen, 2020). Similarly, authors such as Parlakkiliç (2017); Mwapwele et al. (2019); Torres and Giddie (2020) have stated that the benefits of online learning include the possibility of teaching and learning anytime and anywhere (remotely), engaging a diverse audience, cost-effectiveness, increased access to online information, the use of tools to measure learning outcomes and facilitated collaboration between students and educators. However, this study has sought to explore the strategies employed by lecturers to achieve the benefits of teaching and learning via online platforms.

\subsection{Teaching Methodologies and Strategies for Online Learning}

Teaching strategy generally refers to the methods used by an instructor during the teaching process to achieve the lesson outcomes. Famous teaching strategies used during traditional face-to-face learning include lecture, case method, discussion, cooperative learning (small group), brainstorming, and active learning. Since the new way of teaching in higher education institutions is via an online learning platform, it is essential to understand the benefits and challenges of the teaching strategies employed by university lecturers during online teaching. Several authors have indicated that students assimilate information and learn more effectively via online learning than traditional face-to-face learning (Coman et al., 2020; Navarro \& Shoemaker, 2000). Similarly, Burac, Fernandez, Cruz, and Cruz (2019) revealed that teachers attested to the potential benefits of online learning to enhance the educational 
process, improve collaboration and communication with students, provide flexibility, and help students understand lectures better.

In contrast, however, Yusuf and Al-Banawi (2013) stated that some factors, such as lack of physical presence of classmates, demotivated students, and delayed feedback from lecturers negatively affected teaching effectiveness on online learning platforms. Coman et al. (2020) argued that these impediments can be overcome by teachers who adapt teaching strategies according to the needs of their students. As a result, this study seeks to explore the teaching and assessment strategies used by university teachers on online learning platforms to identify their benefits and challenges.

\subsection{Online Learning Assessment Strategies}

In this period of sudden and multiple changes in the mode of teaching and assessment (from traditional to online learning) in higher education institutions, it is important to understand the assessment strategies used by lecturers to assess students in terms of what they know, how well they understand it, as well as how well they can apply what they have learned. Assessment should be part of the teaching process and should serve to show how the students have achieved the learning outcomes. Kearns (2012) stated that student assessment deserves special attention. Assessment includes how lecturers assess students' progress through formative and summative processes, grade students, and provide practical feedback and strategies. In addition, Arend (2007) identified online assessment methods that include online discussion, exams, written assignments, practical assignments, problemsolving assignments, quizzes, journals, projects, and presentations. Gaytan and McEwen (2007) argued that the various assessment methods, particularly methods such as projects, portfolios, self-assessments, peer evaluation, peer evaluation with feedback, timed tests, quizzes, and asynchronous discussion are compatible with online learning platforms. These studies were, however, conducted before the COVID-19 school restrictions, and instructors could take their time planning and preparing for online assessment. Hence, there remains a need to explore the strategies used by lecturers to conduct assessments given the sudden move to exclusively online learning, particularly to understand the benefits and challenges encountered by university lecturers while conducting assessments via online platforms. Knowledge of the benefits and challenges of online assessment will help to identify what is working and the issues that need attention to achieve an authentic and practical assessment.

\subsection{Conceptual Framework}

The conceptual framework of this study is based on the SWOT model, which is an analytical approach commonly used to inform strategic planning and decision-making (De los Santos \& Zanca, 2018). Though the SWOT analysis emerged from practice and lacked a theoretical foundation (Gürel \& Tat, 2017), it was initially developed as a business tool to aid decision making and has since been used to analyze strategies in higher education (Longhurst et al., 2020). The SWOT framework consists of four components, namely strengths, weaknesses, opportunities, and threats. The strengths and weaknesses are best viewed as internal components that could hinder or support lecturers in conducting teaching and assessment during the COVID-19 school restrictions. These strengths and weaknesses also reflect the advantages and disadvantages of conducting online teaching and assessment during the COVID-19 school restrictions. On the other hand, opportunities and threats (ongoing challenges) are considered external components that are likely to have a positive or negative impact, respectively, on lecturers' choice of online teaching and assessment approaches during the pandemic.

Fundamental to the application of SWOT in this study is the examination of the context of the instructional strategy, the analysis of the institution's internal operations and its external environment, and how the latter has shaped the institution's position during the pandemic. Given the wide range of challenges confronting educational institutions due to the COVID-19 lockdown restrictions, conducting a SWOT analysis could provide insight into areas of focus for strategic planning of instructional strategies that can be used to facilitate effective online teaching and assessment modalities in South African Universities during the pandemic. It is also hoped that the SWOT framework will provide an objective and critical perspective of the identified opportunities and challenges of the online teaching and assessment methods applied in South African Universities during the COVID-19 pandemic.

\section{Methodology}

Using a qualitative approach, semi-structured interviews were conducted with five lecturers from three universities in Gauteng Province, South Africa. The collected data was analysed using content analysis.

To achieve the objectives of the study, a qualitative research approach was used to obtain first-hand information in the research setting (Neuman, 2011) and to interpret and understand the participants' experiences of teaching and assessment via an online learning platform (Babbie \& Mouton, 2015). The interaction between the researchers and the participants provided a more accurate understanding of the benefits and challenges of teaching and assessment via an online platform during the school lockdown.

This study employed a multiple case study research design, as it was deemed most appropriate to obtain various types of information from various perspectives (Baxter \& Jack, 2008). The study focused on three Universities in Gauteng Province to provide answers to the research questions. Case studies permit time to be spent in the setting of the research subject (Hamilton \& Corbett-Whittier, 2013). While the interview sessions were conducted virtually, a minimum of one hour was spent online with each participant to understand their point of view. The interview sessions were recorded and later transcribed by the researchers.

\subsection{Data Collection}

The data was generated through semi-structured interviews with 5 participants. The interview data was used to understand the participants' experiences of teaching and assessment strategies used on online learning platforms. The recorded interview sessions helped achieve a word-for-word understanding of what happened during the interview and gave first-hand information for validity and reliability checks. 


\subsection{Sampling}

The participants were purposively sampled to explore their experience of the teaching and assessment strategies used on online learning platforms. Purposive sampling allowed the researchers to identify and choose lecturers who were the most likely to offer rich data. The following criteria were used to purposively select the participants: the participating University must be in Gauteng Province, the lecturer must have been teaching at the university for a minimum of three years, and the lecturer must facilitate module(s) via an online platform during the COVID-19 school restrictions.

\subsection{Participants}

Details of the participants' biographical information are provided in Table 1.

Table-1. Biographical information of participants.

\begin{tabular}{c|c|c|l|c}
\hline & Pseudonyms & Age & Highest Qualification & Years of Experience \\
\hline 1. & Ms. Banta & 40 & Master's in Education Management, Leadership, and Policy & 7 \\
\hline 2. & Ms. Oliphant & 30 & Master's in Mathematics Education & 3 \\
\hline 3. & Ms. Asanam & 38 & Ph.D. Science Education & 4 \\
\hline 4. & Ms. Bulo & 34 & Masters of Education & 3 \\
\hline 5. & Ms. Walette & 35 & Ph.D. Education & 3 \\
\hline
\end{tabular}

\subsection{Data Analysis}

In this study, data analysis was conducted using content analysis. Content analysis was deemed suitable as it helped the researchers to analyze and understand the lecturers' experiences of the teaching and assessment strategies used on an online platform (Erlingsson \& Brysiewicz, 2017). The research questions and conceptual framework also guided the researchers to systematically analyze the data through sorting and interpreting. Thus, the researchers assigned the contents to the categories of strengths, weaknesses, opportunities, or threats for SWOT analysis.

\subsection{Ethical Considerations}

The researchers considered participants' rights throughout the process of the study. Before data was collected, the aims and purpose of the study were explained to all the participants. The participants were told that they could withdraw from the study at any time after they had given their consent to participate. The participants were informed that their real identity or that of their college would not be disclosed. Hence, pseudonyms will be used. Other ethical considerations were satisfied by ensuring that the participants had read, understood, and signed the consent form before the interview sessions.

\section{Findings}

The following discussions provide answers to the three research questions stated above.

What teaching methodologies are used by lecturers to facilitate online learning during the COVID-19 school restrictions?

Participants indicated that before the COVID-19 pandemic, most had conducted teaching in a hybrid or blended form, incorporating both face-to-face and online components for instructional delivery and facilitation of student learning, as practiced in their respective universities. However, all of them were forced to shift their courses entirely online due to the COVID-19 lockdown restrictions. Transitioning to a fully online teaching method, all of the participants indicated that they engaged students in classroom discussions using the online discussion board/chat rooms of the digital platforms utilised. For instance, Ms. Bulo said, "I continued using constructivism as the instructional methodology, and the key contribution to the success of my teaching method is the ability to give students readings and activities to do before coming to class. So, during the online class, I just engage them in discussions on what they had learned before coming to class." Ms. Walette, on the other hand, mentioned that she usually creates a weekly to-do list for her students. Other participants reported using instructional strategies such as pre-recorded presentations and case study activities to facilitate online learning and interaction among students during the COVID-19 school restrictions.

I usually upload study materials a week before the actual lecture date, and I encourage the students to study the materials. During the actual class, I only give an introduction while I call upon students to answer questions related to each aspect of the subject. Sometimes I provide them with case study activities that will require their critical thinking to participate. To ensure that most students are involved in this type of teaching method, I usually explain to my students at our first meeting how things will work so they can be aware and prepared. Sometimes I also give group activities regarding the topic of instruction where all the students in a group will be required to play a role in the learning activities (Ms. Bansa).

I usually use the flip approach where students are already given the course content, additional reading materials and required to download a pre-recorded presentation. So they are encouraged to listen to the presentation and read up on the topic before the class. Then during the actual online class, I randomly select students to explain a concept, and from there, we begin our discussion using the chat options and sometimes the audio functionality of the platform as well (Ms. Asanam).

What methods of assessment are used by lecturers on online platforms during COVID-19 school restrictions?

Assessment is an integral part of teaching and learning that determines whether or not the learning objectives (or outcomes) are being met, as expressed in the curriculum or study guide. The use of different assessment approaches and strategies to assess learning outcomes during a course of study is assumed to be very important in education. One of the aims of this study is to understand how lecturers conduct assessments to make students' learning visible, particularly during the school lockdown restrictions brought about by the COVID-19 pandemic. The participants indicated that not all aspects of students' learning could be assessed online; however, some of them were able to assess students based on their interactions during the online class. For instance, Ms. Banta 
mentioned that she was able to ask questions and provide feedback to her students during synchronous online classes, which is a form of formative assessment. And for the summative assessment, she gives students assignments and also allows students to take a test online using the University's Blackboard collaborative platform. Additionally, she mentioned that data collection of both formative and summative assessments on online platforms should come from different sources and be carried out over time to obtain a true picture of students' learning. Some of the participants also mentioned the various assessments methods they utilized to determine how students were able to meet outlined learning objectives during the COVID-19 school restrictions.

Yes, I use interactive slides and videos, online tests, and students compile a portfolio that they submit at the end of the semester (Ms. Walette).

Basically, I use the computer-based test format which involves a combination of videos clips, quizzes, and slide shows, as well as an online project in the form of an assignment to evaluate my students (Ms. Oliphant).

I administer fun quizzes in the form of games using the Kahoot application, which helps the students review the science content they are learning and how they can also apply it in their classrooms. I also used a Google document where I could create surveys and open-ended questions for students to answer. Sometimes, I assess students' understanding of what is being taught through discussion using the chatroom on Blackboard collaborate. During the discussion, students can interact and evaluate each other's ideas. This allows them to reflect upon their knowledge before writing anything in the chat box (Ms. Asanam).

How does the online environment facilitate or constrain effective teaching and assessment during the school lockdown restrictions?

Participants' responses to the question of how the online environment/platform facilitated or constrained teaching and assessment during the COVID-19 school restrictions were categorized into four themes, based on the elements of SWOT analysis discussed in the conceptual framework. Thus, a detailed description of the lecturers' views is provided below, classified according to the strengths (advantages), weaknesses (disadvantages), opportunities, and threats (ongoing challenges) inherent in using particular teaching and assessment methods in online environments.

\subsection{Strengths}

Concerning the strengths, all the participants indicated that transitioning to a fully online mode of teaching during the lockdown restrictions compensated for the suspension of face-to-face classes with students and gave more opportunities for developing improved educational resources and activities for students. Some participants mentioned how transitioning to online teaching enhanced student interaction, collaborative learning, and engagement in a community of practice. This was noted by Ms. Asanam, who said, "I feel the online platform helps to create a kind of professional learning community which offers a more effective, interactive, and collaborative practice among students and even the lecturer. Another major thing I think can be viewed as the strength of this online teaching is that, for instance, the formative assessments I usually carry out via the Kahoot platform tend to help the students get more involved in learning. I feel this is very motivating." This was confirmed by Ms. Wallete when she mentioned that a significant advantage of online teaching was that her students could engage with one another using the breakout rooms on Google Meet for small group discussions.

Furthermore, participants also indicated that online teaching offers the opportunity to use diverse techniques and means to present content to students. For instance, Ms. Bulo expressed that a fundamental aspect of online teaching is the ability to record the lesson/class, which makes it easy for students to access and listen to the recorded material at any time without the fear of missing classes or not being able to revisit what the lecturer said in a face-to-face classroom. This view was also expressed by Ms. Bansa, who said "With Blackboard, there are various means of engaging learners; for example, you can have a live session, you can upload pre-recorded lectures, you can upload videos, articles and other useful learning materials which the students can access at any time. Another benefit is that students can refer back to the recorded lectures as many times as they want, and this is not possible during a traditional face-to-face lecture. Students can be assessed and get feedback, and also get to know their mark."

\subsection{Weaknesses}

During the interview, lecturers were asked to reflect on the disadvantages and/or internal factors that inhibited their ability to effectively conduct teaching and assessment via online platforms during the school lockdown restrictions. It was found that most of the participants complained about time. However, the lecturers' complaints about time concerned both the time required to design instructions and the time for student learning. All the participants mentioned that they spend more time preparing for online teaching compared to face-to-face teaching. Their preparation includes designing the lesson content, recording and uploading the audio/video, and following up with students to ensure they get the material before the class. Responses to time as a weakness in relation to student learning was noted when Ms. Bulo stated that "In a normal face-to-face class, we have the whole time to ourselves and can even fix extra classes to carry out some work, but in online teaching, time constitutes a hindrance, particularly when using small-group learning methods via the online platform. We do not have enough time for all the groups to present online. This seems a major weakness to me because I cannot engage all the students as desired." On a related note, Ms. Oliphant indicated that students are not compelled to attend synchronous online lectures, unlike in traditional classes where marks are given for class attendance. So students are sometimes excused from attending online classes, while lecturers always have to record the teaching sessions for those who are not able to participate in the online class. Ms. Asanam, on the other hand, mentioned that most of the students are undisciplined when it comes to learning online, probably because they are not able to effectively manage their time and lack basic multitasking skills. Thus, she indicated that this could result in students learning in isolation, particularly during this time of COVID-19. Another concern relates to a lack of communication and cordial relationships with lecturers, which was also raised as a weakness. This was observed by Ms. Wellete, who said "during contact lectures, students are allowed to freely engage with the lecturer and their peers, whereas online it becomes difficult for them to keep on track with their work, as it is difficult for the lecturers to engage one on one with the students". However, Ms. Bansa indicated that sometimes it is not the platforms that constrain effective learning but the attitude of the lecturer or student towards the online 
platform, particularly when lecturers and students are new to the platform. She said "a particular platform might have the necessary online features that can facilitate effective learning, but some lecturers may see the platform as not working or boring and this negatively affects the learning process. More so, some lecturers are just not ready to adapt to change. I say this because I know a few lecturers who still complain about lecturing on Blackboard."

\subsection{Opportunities}

From the analysis of the interviews, it was found that the participants believed that the COVID-19 pandemic seems to have presented many opportunities to lecturers, students, and universities, despite its chronic disruption to curricula. This was evident from their responses to the question asking them to describe the favourable external factors that were and/or could be exploited by students, lecturers, and universities to maximize the benefits of online teaching and assessment during the school lockdown restrictions. For instance, Ms. Oliphant indicated that the lockdown allowed universities to provide disadvantaged students with laptops and airtime data to enable them to continue their work from home. Given this, she feels that it was an opportunity for some students and even lecturers to access the resources needed for online learning for free or at a reduced price. In addition, participants also mentioned that online teaching during the COVID-19 school restrictions provided more learning opportunities for independent work among students. This was succinctly expressed by Ms. Wallete, who said, "This online teaching has created opportunities for the serious students to engage more in self-study and research more articles related to their field. This prepares them for academic writing in their post-graduate studies." In the analysis, it was also found that some participants mentioned the flexible schedules associated with working remotely as an external condition that has helped them to maximize some of the advantages of online learning. Participants further explained how remote working can be perceived as an opportunity. For example:

I think being able to work in a quiet environment that has no background noise as a lecturer and student is a key factor that needs to be considered because all the parties can concentrate and contribute to the teaching and learning process. I feel this is an opportunity that will help improve the quality of online learning during the pandemic. Another external condition that has improved the quality of how I teach via online platforms is the kind of support given by the universities to teaching staff. When lecturers are sufficiently trained in the use of online platforms and emergent technologies, it will improve the quality of their teaching (Ms. Bansa).

Working from home in a quiet space with no interruptions is a significant advantage I see here. And for the students, I believe this is an excellent opportunity for them to succeed because they have unlimited access to online resources, their notes, and people assisting them as they write, especially when doing take-home tests and/or exams (Ms. Bulo).

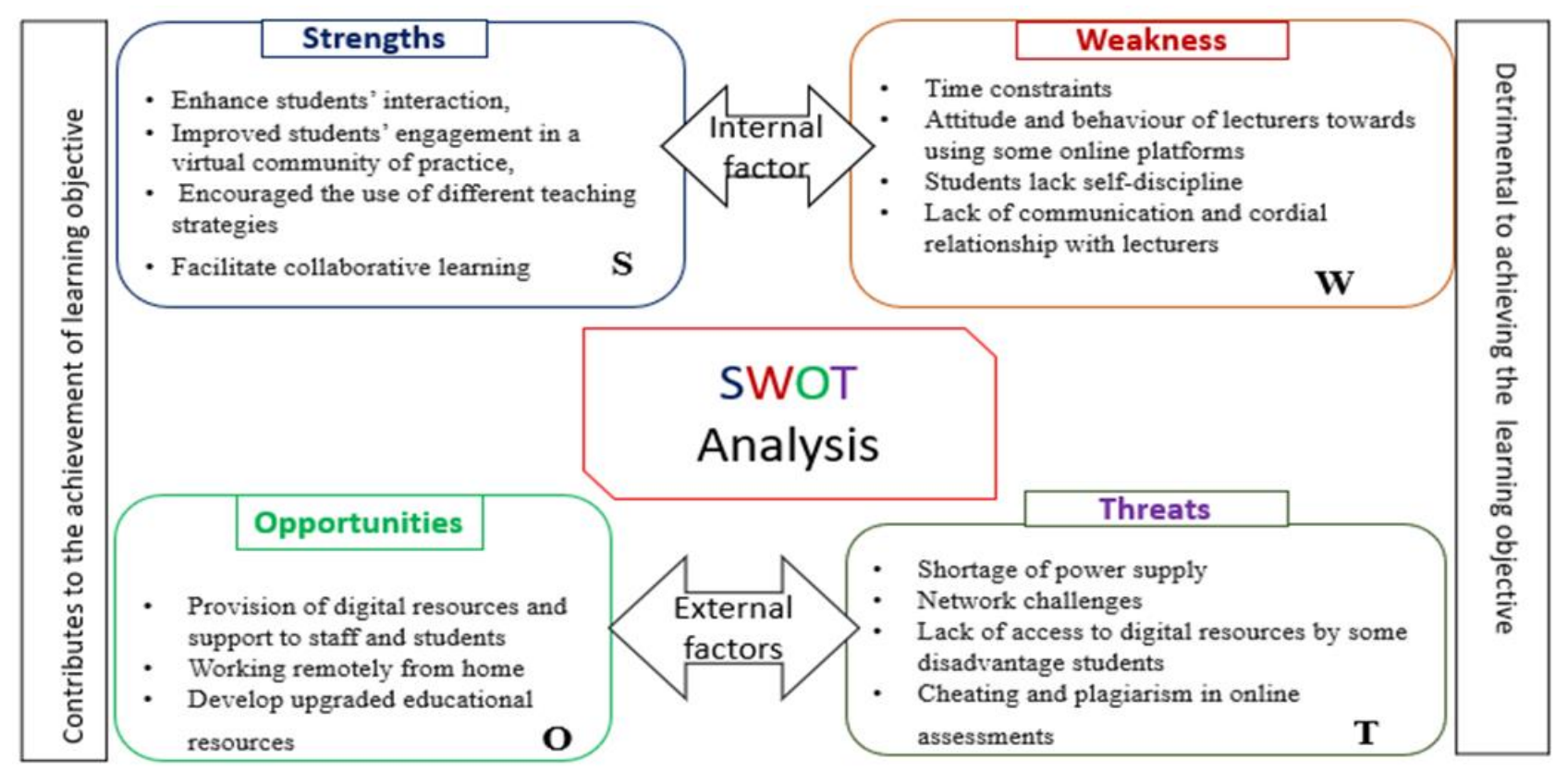

Figure-1. Summary of recurrent themes based on SWOT analysis.

\subsection{Threats}

The data analysis showed that participants also identified external factors that hinder students and lecturers from meeting their learning objectives, as well as hindering the quality of teaching and assessment on online platforms. All the participants mentioned network challenges and a lack of access to resources such as computers, laptops, and the internet (data) as threats to effective online learning. For instance, Ms. Bansa identified external influences that negatively affect the quality of teaching through online platforms that include a lack of online gadgets such as laptops or mobiles, and data and Wi-Fi connections. She further explained that students often complain that they have insufficient data to go online, whereas other times there are connectivity issues. In addition, she indicated that she had been logged out of online classes many times because of poor connectivity, which disrupts the learning process. Participants' concerns about network challenges and lack of resources were also noted when Ms. Wallete said, "some students do not have an internet connection, and some don't have gargets for online teaching. To accommodate all students, a recorded session is sent to them so that they can watch the sessions when they have internet. Some students struggle with connectivity. And for that reason, I make the activities available for the whole week. The portfolio, which is the exam, is open for the whole semester."

Another external factor that all participants commonly mentioned as a threat to online teaching during the COVID-19 school restrictions is power outages, which are referred to as "load shedding." For example, Ms. Bansa said, "I can remember, sometimes I have canceled my class because of load shedding (electricity outage)." Other external factors that participants identified as threats include cheating and/or plagiarism. This was noted by Ms. Bulo, who 
said, "In terms of assessment, the online platforms do not restrict the submission of written assignments. I encountered a problem when I gave an assignment to my students and discovered they were submitting work that was not their own, even going so far as to hire other people to write on their behalf." Similarly, regarding cheating and dishonesty in online assessment, Ms. Wallete indicated, "in one of my online tests, almost all the students had a 100\% score, so I suspected that they had sought external help, maybe someone providing answers to them, which does not happen during the traditional written test in the classroom. So I think sometimes we cannot completely state that online assessment is truthful."

A summary of the recurrent themes generated from participants' responses based on the SWOT analysis is presented in Figure 1.

\section{Discussion and Conclusion}

The effect of COVID-19 lockdown restrictions on almost all aspects of society and daily life has prompted many universities to reshape how education/information is organized and communicated to students and staff. This research has explored the benefits and challenges of conducting teaching and assessment through online platforms during the COVID-19 school lockdown restrictions in South Africa. Participants in this study explained how they tackled online teaching and assessment in their respective universities during the pandemic. In line with the assertion of Rapanta, Botturi, Goodyear, Guàrdia, and Koole (2020) that university faculty and staff had to urgently transition from hybrid to fully online teaching, we argue that university lecturers who use a combination of different digital tools and resources, as well as spend a lot of time adapting new strategies, such as small group work and recording of lecture audio and video, might be able to design, organize and conduct a meaningful online teaching and learning experience during the COVID-19 school restrictions. Moreover, participants reported that they conducted formative and summative assessments remotely, using several methods including students' contributions to online discussions, project-based activities, e-portfolios, Turnitin assignments, interactive video assessments, take-home assessments, multiple-choice, and online quizzes. This implies that although institutions of higher learning wanted to be able to continue effective teaching during the lockdown restrictions, they were also able to use various assessment data to identify students' skills and academic progress while ensuring that learning continued and students could acquire additional strategies for learning (Guangul, Suhail, Khalit, \& Khidhir, 2020).

This paper has specifically documented the benefits and challenges of exclusively online teaching during the COVID-19 school lockdown restrictions using a SWOT analysis. Factors such as enhanced student interaction, improved student engagement in a virtual community of practice, the encouragement of different teaching strategies, and the facilitation of collaborative learning were reported as perceived strengths of online learning during the COVID-19 school lockdown restrictions. Time constraints, the attitudes and behaviors of lecturers towards using online platforms, students' lack of self-discipline, and a lack of communication and cordial relationships with lecturers were identified as weaknesses. Identified opportunities included the provision of digital resources and support to staff and students, the advantages of working remotely from home, as well as the opportunity to develop upgraded educational resources. Power outages, network challenges, the lack of access to digital resources for some disadvantaged students, and cheating and plagiarism in online assessments were considered threats. To achieve success in online teaching, institutions seek a competitive advantage that can be found within, particularly when identified strengths are matched with opportunities that can uniquely shape institutional decisions and outcomes (de los Santos and Zanca, 2018). Hence, this study recommends that now more than ever, universities invest in the professional development of their faculty staff to ensure they are up to date on effective pedagogical and assessment methods using online technologies. It is also recommended that universities incorporate online learning platform tools to help reduce the dishonesty of online assessment, which threatens the ability to offer quality teaching and learning in our universities.

\section{References}

Anwar, K., \& Adnan, M. (2020). Online learning amid the COVID-19 pandemic: Students perspectives. Journal of PedagogicalSsociology and Psychology, 1(2), 45-51.Available at: https://doi.org/10.33902/jpsp.2020261309.

Arend, B. (2007). Course assessment practices and student learning strategies in online courses. Journal of Asynchronous Learning Networks, $11(4), 3-13$. Available at: https://doi.org/10.24059/olj.v1 1i4.1590.

Babbie, E., \& Mouton, J. (2015). The practice of social research. London: Oxford University Press.

Barrett, B. (2010). Virtual teaching and strategies: Transitioning from teaching traditional classes to online classes. Contemporary Issues in Education Research, 3(12), 17-20.Available at: https://doi.org/10.19030/cier.v3i12.919.

Baxter, P., \& Jack, S. (2008). Qualitative case study methodology: Study design and implementation for novice researchers. The Qualitative Report, 13(4), 544-559.Available at: https://doi.org/10.46743/2160-3715/2008.1573.

Burac, M. A. P., Fernandez, J. M., Cruz, M. M. A., \& Cruz, J. D. (2019). Assessing the impact of e-learning system of higher education institution's instructors and students. Paper presented at the IOP Conference Series: Material Science and Engineering.

Coman, C., Țîru, L. G., Meseşan-Schmitz, L., Stanciu, C., \& Bularca, M. C. (2020). Online teaching and learning in higher education during the coronavirus pandemic: Students' perspective. Sustainability, 12(24), 1-22.Available at: https://doi.org/10.3390/su122410367.

De los Santos, E., \& Zanca, N. A. (2018). Transitioning to online: A SWOT analysis by first-time online business faculty. E-Journal of Business Education and Scholarship of Teaching, 12(3), 69-84.

Erlingsson, C., \& Brysiewicz, P. (2017). A hands-on guide to doing content analysis. African Journal of Emergency Medicine, 7(3), 9399.Available at: https://doi.org/10.1016/j.afjem.2017.08.001.

Gaytan, J., \& McEwen, B. C. (2007). Effective online instructional and assessment strategies. The American Journal of Distance Education, 21(3), 117-132.Available at: https://doi.org/10.1080/08923640701341653.

Guangul, F. M., Suhail, A. H., Khalit, M. I., \& Khidhir, B. A. (2020). Challenges of remote assessment in higher education in the context of COVID-19: A case study of Middle East College. Educational Assessment, Evaluation and Accountability, 32(4), 519-535.Available at: https://doi.org/10.1007/s1 1092-020-09340-w.

Gürel, E., \& Tat, M. (2017). SWOT analysis: A theoretical review. Journal of International Social Research, 10(51), 994 - 1006.Available at: https://doi.org/10.17719/jisr.2017.1832.

Hamilton, L., \& Corbett-Whittier, C. (2013). Defining case study in education research. In Using case study in education research. North America: Sage Publications.

Hew, K. F., \& Cheung, W. S. (2014). Students' and instructors' use of massive open online courses (MOOCs): Motivations and challenges. Educational Research Review, 12, 45-58.Available at: https://doi.org/10.1016/j.edurev.2014.05.001.

Kearns, L. R. (2012). Student assessment in online learning: Challenges and effective practices. Journal of Online Learning and Teaching, 8(3), $198-208$. 
Longhurst, G. J., Stone, D. M., Dulohery, K., Scully, D., Campbell, T., \& Smith, C. F. (2020). Strength, weakness, opportunity, threat (SWOT) analysis of the adaptations to anatomical education in the United Kingdom and Republic of Ireland in response to the Covid-19 pandemic. Anatomical Sciences Education, 13(3), 301-311.Available at: https://doi.org/10.1002/ase.1967.

Marinoni, G., Van't Land, H., \& Jensen, T. (2020). The impact of Covid-19 on higher education around the world. IAU Global Survey Report.

Mwapwele, S. D., Marais, M., Dlamini, S., \& Van Biljon, J. (2019). Teachers' ICT adoption in South African rural schools: A study of technology readiness and implications for the South Africa connect broadband policy. The African Journal of Information and Communication, 24, 1-21.Available at: https://doi.org/10.23962/10539/28658.

Navarro, P., \& Shoemaker, J. (2000). Performance and perceptions of distance learners in cyberspace. American Journal of Distance Education, 14(2), 15-35.Available at: https://doi.org/10.1080/08923640009527052.

Neuman, W. L. (2011). Social research methods. Qualitative and quantitative approaches (7th ed.). New York: Allyn and Bacon.

Parlakkiliç, A. (2017). Change management in transition to e-learning system. Qualitative and Quantitative Methods in Libraries, 3(3), 637-651.

Ramorola, M. Z. (2013). Challenge of effective technology integration into teaching and learning. Africa Education Revierw, 10(4), 654670.Available at: https://doi.org/10.1080/18146627.2013.853559.

Rapanta, C., Botturi, L., Goodyear, P., Guàrdia, L., \& Koole, M. (2020). Online university teaching during and after the Covid-19 crisis: Refocusing teacher presence and learning activity. Postdigital Science and Education, 2(3), 923-945.Available at: https://doi.org/10.1007/s42438-020-00155-y.

SAP Litmos. (2021). Understanding E-learning platform. Retrieved from https://www.litmos.com/platform/e-learningplatformdefinition\#: :text=A\%20online\%20learning\%20platform\%20is, enhance\%20education\%20delivery\%20and\%20managemen $\underline{\mathrm{t}}$.

Torres, K. M., \& Giddie, L. (2020). Educator perceptions and use of technology in South African schools. Peabody Journal of Education, 95(2), 117-126.Available at: https://doi.org/10.1080/0161956x.2020.1745611.

Yusuf, N., \& Al-Banawi, N. (2013). The impact of changing technology: The case of e-learning. Contemporary Issues in Education Research, 6(2), 173-180. 